\title{
Performance Analysis of Preamble Detection at Maximum Throughput Level for OFDM
}

\author{
Ayushi Upadhyay \\ Department of Electronics and Communication, LNCT Indore, Madhya Pradesh, India
}

\begin{abstract}
How to cite this paper: Ayushi Upadhyay "Performance Analysis of Preamble Detection at Maximum Throughput Level for OFDM" Published in International Journal of Trend in Scientific Research and Development (ijtsrd), ISSN: 24566470, Volume-3 | Issue-3, April 2019, pp.535-536, URL: http://www.ijtsrd.co $\mathrm{m} /$ papers/ijtsrd213 80.pdf

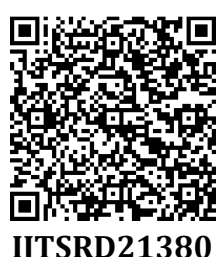

Copyright (C) 2019 by author(s) and International Journal of Trend in Scientific Research and Development Journal. This is an Open Access article distributed under the terms of the Creative Commons Attribution License (CC BY 4.0)

(http://creativecommons.org/licenses/ by/4.0)

\section{INTRODUCTION}

WiMAX (Worldwide Interoperability for Microwave Access) is a family of wireless communication standards based on the IEEE 802.16 set of standards, which provide multiple physical layer (PHY) and Media Access Control (MAC) options. The IEEE 802.16 group was formed in 1998 to develop an air interface standard for wireless broadband. The group's initial focus was the development of a LOSbased point-to-multipoint wireless broadband system for operation in the $10 \mathrm{GHz}-66 \mathrm{GHz}$ millimeter wave band. The resulting standard-the original 802.16 standard, completed in December 2001-was based on a single carrier physical (PHY) layer with a burst time division multiplexed (TDM) MAC layer.

\section{Methods of Preamble Detection}

In simple terms, preamble is used to communicate to the receiver that transmitted data is on the way. In the context of Wi-Fi (802.11) Technology, Preamble allows the receiver to acquire the wireless signal and synchronize itself with the transmitter. In wireless OFDM systems like WiMAX (802.16e), preamble is first symbol of the downlink transmission which is used for initial frame timing/synchronization by mobile stations. Initially, when a
MS (Mobile Station) enters a network, it has to search for the neighboring BSs (Base Station) in order to achieve synchronization. Preamble detection is done for the synchronization and synchronization is done in the basis of two types symbol timing and carrier frequency offset. OFDM has been shown to be sensitive to symbol timing errors. Symbol timing estimation is typically performed in two steps:

1. Course estimate in the time domain,

2. Fine estimate in the frequency domain.

\section{Simulation Results}

In this correlation of preamble detection (maximum normalized correlation (MNC or MINN), Schmidt and Cox maximum normalized correlation (SC or MSC), maximum normalized correlation using a geometric mean (GM or MGM), maximum likelihood (ML or MML) method are comparison on OFDM using AWGN Channel. In this model we have used QAM (Quadrature Amplitude Modulation) in modulation technique, and required SNR value is $25 \mathrm{~dB}$ and $45 \mathrm{~dB}$ the performance done by used MATLAB R2013a version. 


\section{A. Preamble detection in SNR at $25 \mathrm{~dB}$}

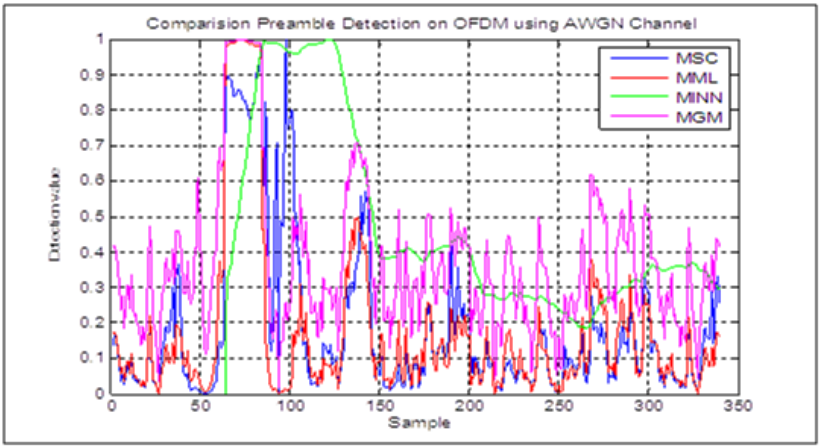

Fig. 1: Correlation between Different signals at SNR=25 dB

Table 1: Performance analysis of Preamble detection at $\mathrm{SNR}=\mathbf{2 5 \mathrm { dB }}$

\begin{tabular}{|c|c|c|c|}
\hline $\begin{array}{c}\text { Preamble } \\
\text { Technique }\end{array}$ & SNR & $\begin{array}{c}\text { Maximum } \\
\text { Detection Value }\end{array}$ & Sample \\
\hline \multirow{2}{*}{ MSC } & \multirow{3}{*}{$25 \mathrm{~dB}$} & 1.0 & 96 \\
\cline { 1 - 1 } \cline { 3 - 3 } MML & 1.0 & 65 \\
\cline { 1 - 1 } MINN & 1.0 & 75 \\
\hline MGM & 1.0 & 65 \\
\cline { 3 - 4 } & & 1.0 & 65 \\
\hline
\end{tabular}

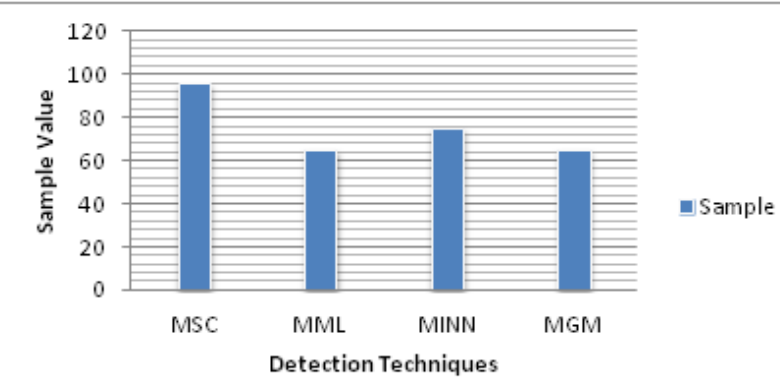

Fig. 2: Comparisons of Detection techniques at $S N R=25 d B$

\section{B. Preamble detection in SNR at 45dB}

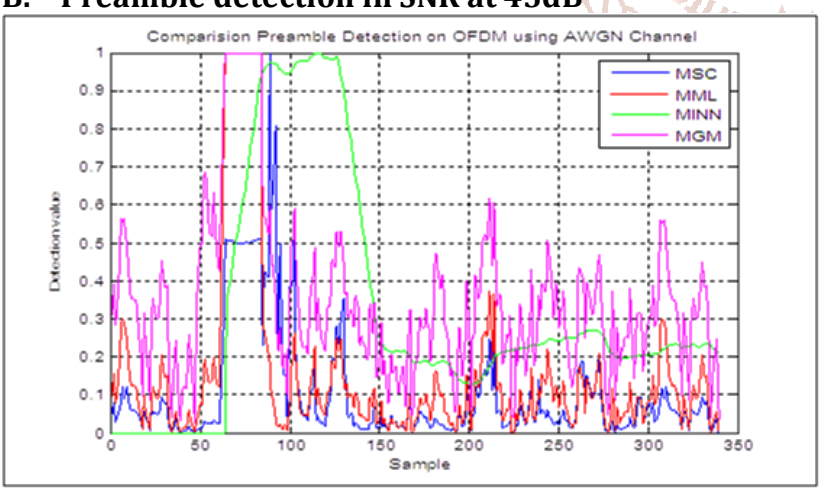

Fig 2: Correlation between Different signals at $\mathrm{SNR}=45 \mathrm{~dB}$

Table 2: Performance analysis of Preamble detection at $\mathrm{SNR}=\mathbf{4 5 \mathrm { dB }}$

\begin{tabular}{|c|c|c|c|}
\hline $\begin{array}{l}\text { Preamble } \\
\text { Technique }\end{array}$ & SNR & $\begin{array}{c}\text { Maximum } \\
\text { Detection Value } \\
\end{array}$ & Sample \\
\hline MSC & \multirow{4}{*}{$45 \mathrm{~dB}$} & 1.0 & 90 \\
\hline MML & & 1.0 & 72 \\
\hline MINN & & 1.0 & 120 \\
\hline MGM & & 1.0 & 65 \\
\hline
\end{tabular}

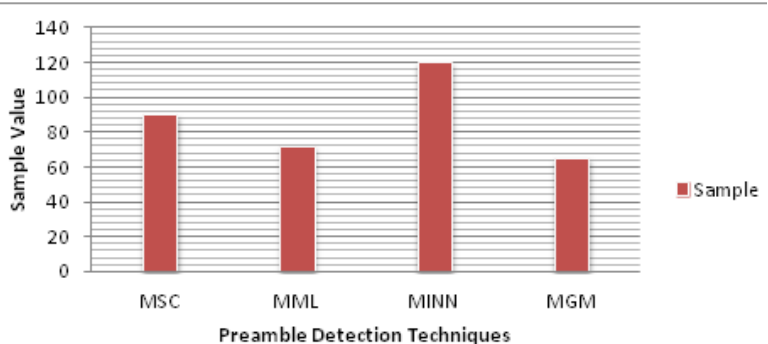

Fig. 4: Comparisons of Detection techniques at $S N R=25 d B$

\section{Conclusion:}

In above result we have done analysis of all preamble techniques (MSC, MML, MSC and MGM) at different SNR value $(25 \mathrm{~dB}$ and $45 \mathrm{~dB})$. The MINN technique is better than all techniques because its performance is smooth. It gradually down and rise at all point so t MINN is better than all techniques.

\section{References}

[1] Sumeeth Nagaraj, Sheehan Khan and Christian Schlegel "On Preamble Detection in Packet-Based Wireless Networks" 2006 IEEE Ninth International Symposium on Spread Spectrum Techniques and Applications.

[2] Mithun Sarode "Preamble Detection Of IEEE 802.16" proceedings of international conference on nanoscience, engineering \& advanced computing (ICNEAC-2011).

[3] Chakchai So-In,Raj Jain and Abdel-Karim Tamimi, "Scheduling in IEEE 802.16e Mobile WiMAX Networks: Key Issues and a Survey" IEEE Journal on Selected Areas in Communications, Vol. 27, NO. 2, February 2009 page no 156-171.

[4] L. J. Cimini, "Analysis and simulation of a digital mobile channel using orthogonal frequency division multiplexing" IEEE Trans. Commun., vol. 33, no. 7, pp. 665-675, Jul. 1985.

[5] P. H. Moose, "A technique for orthogonal frequency division multiplexing freuency offset correction" IEEE Trans. Commun., vol. 42, no. 10, pp. 2908-2924, 1994.

[6] H. MINN, V. K. Bhargava, and K. B. Letaief, "A robust timing and frequency synchronization for OFDM systems" IEEE Trans. Wireless Commun., vol. 2, no. 4, pp. 822-838, Jul. 2003.

[7] T. M. Schmidl and D. C. Cox, "Robust frequency and timing synchronization for OFDM" IEEE Trans. Commun., vol. 45, no. 12, pp. 1613-1621, Dec. 1997.

[8] R. N. "Blind OFDM symbol synchronization in ISI channels" IEEE Trans. Commun., vol. 50, no. 9, pp. 1525-1534, Sep. 2002.

[9] Kun-Chien Hung and David W. Lin "Joint Detection of Integral Carrier Frequency Offset and Preamble Index in OFDMA WiMAX Downlink Synchronization" IEEE Communications publication in the WCNC 2007. Page no 1961-1966.

[10] Jungwon Lee, Jihwan P. Choi, and Hui-Ling Lou "Joint Maximum Likelihood Estimation of Channel and Preamble Sequence for WiMAX Systems" IEEE Transaction on Wireless Communications, VOL. 7, NO. 11, November 2008 page no 4291-4303. 